\title{
Contribuição ao conhecimento de Nyctiborinae (Blattellidae) do Brasil, com a descrição de novos táxons
}

\author{
Sonia Maria Lopes ${ }^{1,2}$ \& Edivar Heeren de Oliveira ${ }^{1}$ \\ Biota Neotropica $v 7(n 1)$ \\ http://www.biotaneotropica.org.br/v7n1/pt/abstract?article + bn00407012007 \\ Recebido em 31/03/06 \\ Versão reformulada recebida 20/11/06 \\ Publicado em 01/01/07 \\ ${ }^{1}$ Departamento de Entomologia, Museu Nacional, Universidade Federal do Rio de Janeiro, \\ Quinta da Boa Vista, CEP 20940-040, São Cristóvão, Rio de Janeiro, Brasil \\ ${ }^{2}$ Autor para correspondência: Sonia Maria Lopes, e-mail: sonialf@acd.ufrj.br
}

\begin{abstract}
Lopes, S.M. \& Oliveira, E.H. Contribution to our knowledge of Brazilian Nyctiborinae (Blatellidae) with descriptions of new taxa. Biota Neotrop. Jan/Apr 2007 vol. 7, no. 1 http://www.biotaneotropica.org.br/v7n1/pt/ abstract?article+bn00407012007 ISSN 1676-0603.

In this paper one new genus (Eushelfordiella) with one new species (Eushelfordiella paraense) are described. A designation of the material type from Para State, Brazil is made. A new combination is proposed by transferring Paratropes amazonensis Rocha e Silva-Albuquerque (1957) to Eushelfordia Hebard, 1926.

Keywords: Eushelfordiella, new genus, new species, Blattaria, Taxonomy, Pará State.

\section{Resumo}

Lopes, S.M. \& Oliveira, E.H. Contribuição ao conhecimento de Nyctiborinae (Blattellidae) do Brasil com a descrição de novos táxons. Biota Neotrop. Jan/Apr 2007 vol. 7, no. 1 http://www.biotaneotropica.org. br/v7n1/pt/abstract?article+bn00407012007 ISSN 1676-0603.

Neste trabalho descreve-se um novo gênero (Eushelfordiella) com uma espécie nova (Eushelfordiella paraense), designada como espécie-tipo, do Estado do Pará, Brasil. Uma nova combinação é proposta, com a transferência de Paratropes amazonensis Rocha e Silva-Albuquerque (1957) para o gênero Eushelfordia Hebard, 1926.
\end{abstract}

Palavras-chave: Eushelfordiella, gênero novo, espécie nova, Blattaria, Taxonomia, Pará. 


\section{Introdução}

Eushelfordiella gen. nov. foi incluído entre os gêneros que atualmente pertencem a Nyctiborinae com base na disposição dos espinhos nas pernas e a tomentosidade geral do corpo (Burmeister 1838).

Neste trabalho são feitas as descrições de um gênero e uma espécie nova com base em um único exemplar (fêmea) coletado no estado do Pará, sendo esta espécie designada como tipo para o gênero. São apresentadas ilustrações do habitus e detalhes do exemplar descrito.

\section{Material e Métodos}

Com objetivo de comparação, foram examinados indivíduos de espécies com atributos similares à espécie aqui descrita. Para isso oito exemplares de Eushelfordia pica (Walker 1868) e três de Paratropes amazonensis Rocha e Silva-Albuquerque (1957) depositados na coleção de Blattaria do Departamento de Entomologia do Museu Nacional foram examinados.

\section{Resultados}

\section{Eushelfordiella gen. nov.}

Diagnose: Coloração geral de fundo amarela com manchas negras bem definidas dispostas no pronoto, pernas e tégminas mediana e apicalmente. Cabeça com artículos antenais tomentosos, gradativamente dilatados, tornando-se filiformes no ápice. Tórax com pronoto pequeno, elíptico triangulóide, com as abas laterais amplas com contorno arredondado; fêmur anterior na face ântero-ventral com uma série cerrada de espinhos pequenos e ciliformes até o ápice, terminando em um espinho apical desenvolvido; face póstero-ventral com espinhos ciliformes; fêmur II e III com uma série de espinhos ciliformes, sem espinho apical.

Etimologia: O nome do gênero deve-se à similaridade no aspecto geral com Eushelfordia Hebard, 1926.

Espécie-tipo: Eushelfordiella paraense sp. nov.

\section{Eushelfordiella paraense sp. nov.}

Material examinado: Holótipo fêmea. BRASIL, Pará: Melgaço, Caxiuanã, ECFPn, 14/VII/1995, R. M. Valente col. (copa 15 m de altura).

Coloração geral: Amarelo-brilhante com manchas negras bem evidenciadas (Figuras 1 e 3), com intensa tomentosidade dourada nas áreas claras e castanho-escura em outras áreas em todo o corpo. Cabeça castanho-clara amarelada com palpos negros (Figura 5); antenas com os três artículos imediatamente localizados após a dilatação castanho-claros (Figura 4). Asas bicoloridas. Pernas, com as bases das coxas e dos fêmures, ápice das tíbias e artículos tarsais castanho escuros quase negros. Abdome com área central castanho-escurecida, região apical e látero-basal castanho-amarelada (Figuras 1, 2).

Cabeça: Pequena e triangular, vértice pouco exposto, apresentando cerdas desenvolvidas; espaço interocular amplo medindo três quartos da área que separa as bases das inserções antenais; olhos pequenos e levemente projetados; antenas longas atingindo o ápice do abdome; artículos antenais tomentosos gradativamente dilatados, da base até o terço apical onde diminui abruptamente em direção ao ápice. Palpos maxilares com primeiro, segundo e quarto artículos pequenos; terceiro artículo desenvolvido e quinto artículo maior, bastante dilatado e tomentoso.

Tórax: Pronoto pequeno, elíptico e triangulóide, transverso, medianamente convexo e levemente côncavo médio-lateralmente; ápice com tênue sinuosidade, abas laterais amplas com contorno arredondado e base angular projetada (Figuras 1,2). Tégminas com intensa tomentosidade, longas e alargadas, ultrapassando em muito o ápice dos cercos. Campo marginal defletido, côncavo, alargado e bem marcado; campo escapular amplo com ramos oblíquos, campo discoidal longitudinal e campo anal bem marcado e levemente convexo. Asas posteriores longas e quando em repouso e em vista dorsal, mostram seu ápice levemente projetado sob as tégminas. Pernas com fêmures desenvolvidos, com espinhos muito finos e ciliformes; tíbias com espinhos fortes. Fêmur anterior apresentando na face ântero-ventral uma série cerrada de espinhos ciliformes até o ápice e um espinho apical grande e desenvolvido; face póstero-ventral com espinhos ciliformes, pouco maiores e pouco mais espaçados que a face ântero-ventral. Fêmures médio e posterior com uma série de espinhos ciliformes, semelhante na ântero e na póstero-ventral, sem espinhos apicais; presença de espinhos geniculares robustos. Tarsos robustos; pulvilos desenvolvidos em todos os quatro artículos tarsais; arólio grande semelhante em tamanho à unha menor; unhas assimétricas e não especializadas.

Abdome: Ápice do abdome com placa supra-anal projetada entre os cercos, com ápice arredondado e com reentrância pouco acentuada; cercos pequenos e de ápice arredondado, ambos bastante tomentosos. Placa subgenital ampla e globosa, com margem apical arredondada.

Dimensões (mm): Holótipo + . Comprimento total: 20,0; comprimento do pronoto: 4,0; largura do pronoto: 6,5; comprimento da tégmina: 17,0; largura da tégmina: 6,0.

Etimologia: O nome da espécie deve-se ao local (Estado) de coleta do exemplar.

\section{Eushelfordia amazonensis (Rocha e Silva-Albuquerque 1957) n. comb.}

Com base na análise do material na coleção de Blattaria do Museu Nacional e em Rocha e Silva-Albuquerque (1957), o estudo comparativo realizado demonstrou que a espécie P. amazonensis se

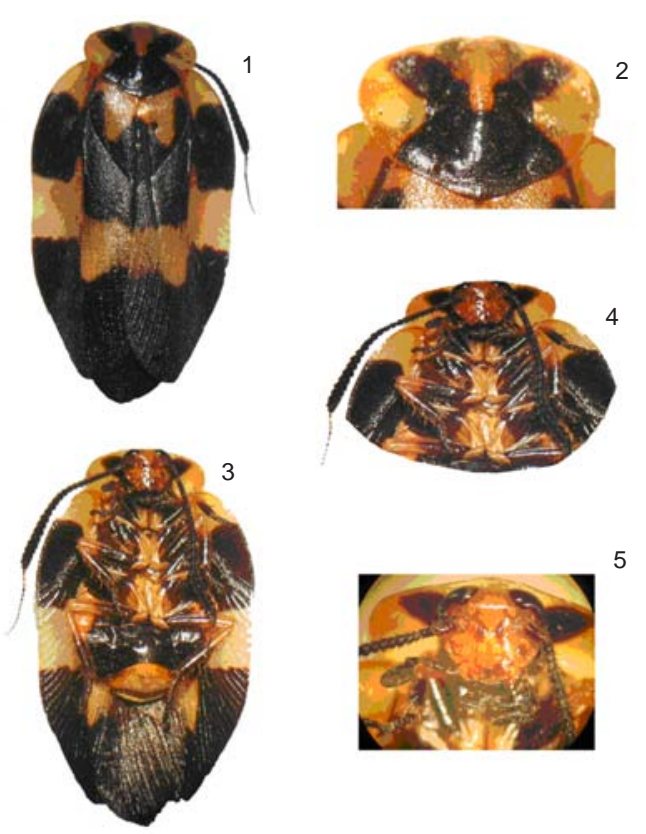

Figuras 1-5. Eushelfordiella paraense sp. nov. fêmea: 1: Habitus, dorsal; 2: Pronoto, dorsal; 3: Habitus, ventral; 4: Antena e 5: Cabeça, ventral.

Figures 1-5. Eushelfordiella paraense sp. nov. female: 1: Habitus, dorsal; 2: Pronoto, dorsal; 3: Habitus, ventral; 4: Antena and 5: Head, ventral. 


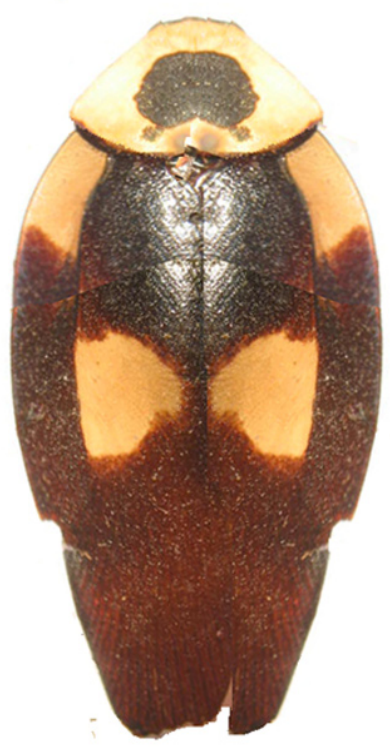

Figura 6. Eushelfordia amazonensis (Rocha e Silva-Albuquerque 1957): holótipo macho, Habitus, dorsal.

Figura 6. Eushelfordia amazonensis (Rocha e Silva-Albuquerque 1957): holotype male, Habitus, dorsal.

encontra incorretamente classificada no gênero Paratropes. Sendo assim, nesse trabalho $P$. amazonensis (Figura 6) é transferida à Eushelfordia, ressaltando os seguintes caracteres: (1) na coloração do exemplar e (2) na configuração do fêmur anterior que apresenta na face póstero-ventral ausência de espinhos pré-apicais e apical; fêmur médio na face póstero-ventral com um espinho na região mediana, fêmur posterior, na face póstero-ventral com dois espinhos na região mediana.

Paratropes Serville, 1839 apresenta a configuração dos espinhos nas pernas diferenciada: (1) a face póstero-ventral do fêmur anterior apresenta três espinhos na metade apical e um espinho apical, (2) o fêmur médio apresenta dois espinhos no terço mediano e (3) o fêmur posterior possui três cerdas na metade apical e um espinho apical.

\section{Referências Bibliográficas}

BURMEISTER, H., 1838. Blattina, In: Handbuch der Entomologie, I.C.F. Enslin. 2(2):469-517.

ROCHA E SILVA-ALBUQUERQUE, I., 1957. Sobre o gênero Paratropes Serv., 1839, com descrição de uma espécie nova. Bol. Mus. Nac., Zool. 150: $1-14$.

Título: Contribuição ao conhecimento de Nyctiborinae (Blattellidae) do Brasil, com a descrição de novos táxons.

Autores: Lopes SM. e Oliveira EH.

Biota Neotropica, Vol.7 (número 1): 2007

http://www.biotaneotropica.org.br/v7n1/pt/abstract?article+bn 00407012007

Recebido em 31/03/06 - Versão reformulada recebida 20/11/06 - Publicado em 01/01/07

ISSN 1676-0603 